\title{
Dynamic Response in a Porous Seabed of Finite Depth to Combined Wave and Current Loadings
}

\section{B. $\mathrm{Liu}^{\dagger}$, D.S. Jeng ${ }^{\dagger *}$, and J.S. Zhang ${ }^{\S}$}

${ }^{\dagger}$ Center for Marine Geotechnical Engineering

Key Laboratory of Ocean Engineering

Shanghai Jiao Tong University

Shanghai 200240, China
*Division of Civil Engineering

University of Dundee

Dundee DD1 4HN, UK
${ }^{\S}$ State Key Laboratory of Hydrology-Water Resources and Hydraulic Engineering

Hohai University

Jiangsu 210098, China

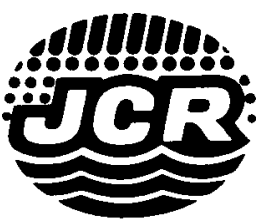

www.JCRonline.org

ABSTRACT

Liu, B.; Jeng, D.S., and Zhang, J.S., 2014. Dynamic response in a porous seabed of finite depth to combined wave and current loadings. Journal of Coastal Research, 30(4), 765-776. Coconut Creek (Florida), ISSN 0749-0208.

In this study a $u-p$ approximation for the dynamic response of a porous seabed to nature dynamic loadings is proposed. Unlike most previous research, the effects of currents are considered in the new analytical solution. Based on the numerical examples, the significant influence of combined wave and current loadings on seabed response in shallow water is concluded. This influence affects not only the amplitudes of the seabed response but also the distributions of the space region. The relative difference of the maximum pore pressure between different direction currents can reach $8 \%$ of the static water pressure. In addition, the relative difference of maximum liquefaction depth between the previous model (without currents) and the present model can reach $19 \%$ of the maximum liquefaction depth of the case without currents.

ADDITIONAL INDEX WORDS: Current, third-order wave/current interaction, liquefaction, pore pressure.

\section{INTRODUCTION}

Recently, the phenomenon of wave/current-seabed structures' interactions has been intensively studied by coastal and geotechnical engineers. The main reason for the growing interest of this problem is that numerous offshore installations have been reported to be damaged for wave-induced seabed instability, rather than construction failure (Lundgren, Lindhardt, and Romold, 1989; Silvester and Hsu, 1989; Sumer and Fredsoe, 2002). Furthermore, the previous study shows that the wave-induced seabed instability in the vicinity of the structures has been considered as one of key factors in the design of coastal structures (Silvester and Hsu, 1989).

It has been well known that when ocean waves propagate over a porous seabed, they can induce dynamic wave pressure on the surface of the seabed and dynamic pore pressure in the seabed. As the phase lags and damping of the dynamic wave pressure occur, the difference between the wave pressure and pore pressure generated the excess pore pressure. When the value of the excess pore pressure exceeds the value of the overburden pressure, the effective stresses will be vanished and the seabed may be liquefied (Rahman, 1997). In this case the seabed solid will become unbound and completely free, and the soil will act like liquid. Therefore, the estimation of the wave-induced soil response (including pore pressure, effective stresses, shear stresses, and soil displacements) is particularly important for coastal and geotechnical engineers involved in the design of the foundations for offshore installations.

Based on Biot's poro-elastic theory (Biot, 1941), numerous investigations for the wave-induced soil response have been

DOI: 10.2112/JCOASTRES-D-12-00064.1 received 26 March 2012; accepted in revision 12 May 2012; corrected proofs received 7 August 2012; published pre-print online 25 February 2013.

*Corresponding author: jengd2@asme.org

(c) Coastal Education \& Research Foundation 2014 carried out since the 1970s. Among these, Yamamoto et al. (1978) considered two-dimensional progressive waves over isotropic and homogeneous seabed with infinite thickness. Later, some progress has been made by considering anisotropic and nonhomogeneous seabed behaviors (Jeng, 1997; Jeng and Seymour, 1997; Kitano and Mase, 1999). In addition to analytical solutions, numerous numerical models and experimental works have been reported in the literature (Cuomo, Allosp, and Takahashi, 2010; Jeng and Lin, 1996; Kudella et al., 2006; Sassa et al., 2006; Wen, Jeng, and Wang, 2012; Zen and Yamazaki, 1990; Zhang et al., 2009).

In the Biot's consolidation theory (Biot, 1941) the inertial terms have been ignored. Based on Biot's dynamic poro-elastic theory (Biot, 1956), Zienkiewicz, Chang, and Battess (1980) investigated the effects of inertial terms on the earthquakeinduced vibration of structures and concluded that the socalled " $u-p$ " approximation is sufficient for most dynamic engineering problems. Jeng, Rahman, and Lee (1999) and Jeng and Rahman (2000) introduced Biot's dynamic poro-elastic theory into the problem of wave-induced soil response. Later, Jeng and Cha (2003) and Ulker, Rahman, and Jeng (2009) further clarified the applicable range of the " $u-p$ " approach in the relevant engineering problems. All aforementioned research has been limited to wave loading only, excluding currents. However, it is common that waves and currents coexisted in the marine environments, especially in shallow water. Furthermore, according to the potential flow theory, currents will affect the wave pressure significantly. Therefore, it is necessary to clarify the influence of currents in these engineering problems.

The purpose of this study is to explore the influence of the combined wave and current loadings on soil response for a seabed of finite thickness. To do so, the inertial forces are included in the porous model, and the third-order theory for wave and current 
interactions are considered. Based on the new solution, the influence of currents and wave nonlinearity will be examined.

\section{BOUNDARY VALUE PROBLEM}

\section{Governing Equations}

In this study the wave/current-seabed interactions are illustrated in Figure 1. Both wave crests and currents are assumed to propagate in the positive $x$ direction, while the $z$ direction is positive upward from the seabed surface.

The seabed is treated as isotropic linear elastic in this study, and the soil permeability in the $x$ and $z$ directions are equal. Then, based on the conservation of mass, the consolidation equation with inertial terms (Biot, 1956) can be expressed as

$$
\frac{K}{\gamma_{\omega}}\left(\frac{\partial^{2} p}{\partial x^{2}}+\frac{\partial^{2} p}{\partial z^{2}}\right)-n \beta \frac{\partial p}{\partial t}+\rho_{f} \frac{\partial^{2} \varepsilon}{\partial t^{2}}=\frac{\partial \varepsilon}{\partial t},
$$

where $K$ is soil permeability, $\gamma_{\omega}$ is the unit weight of pore water, $p$ is pore pressure, $t$ is time, $n$ is soil porosity, and $\rho_{f}$ is pore fluid density.

In Equation (1) the third term on the left side is the inertial term, which has been ignored in most previous studies (Madsen, 1978; Yamamoto et al., 1978). The compressibility of pore fluid $(\beta)$ and volumetric strain of the soil matrix $(\varepsilon)$ are defined as (Jeng, 1997; Yamamoto et al., 1978)

$$
\beta=\frac{1}{K_{w}}+\frac{1-S}{P_{w s}} \text { and } \varepsilon=\frac{\partial u}{\partial x}+\frac{\partial w}{\partial z},
$$

in which $S$ is the degree of saturation, $K_{w}$ is the modulus of elasticity of water, $P_{w s}$ is absolute water pressure, and $u$ and $w$ are the soil displacements in $x$ and $z$ directions, respectively.

Under conditions of plane strain the relation between incremental effective stresses and soil displacements are defined as

$$
\sigma_{x}^{\prime}=2 G\left(\frac{\partial u}{\partial x}+\frac{\mu}{1-2 \mu} \varepsilon\right)
$$

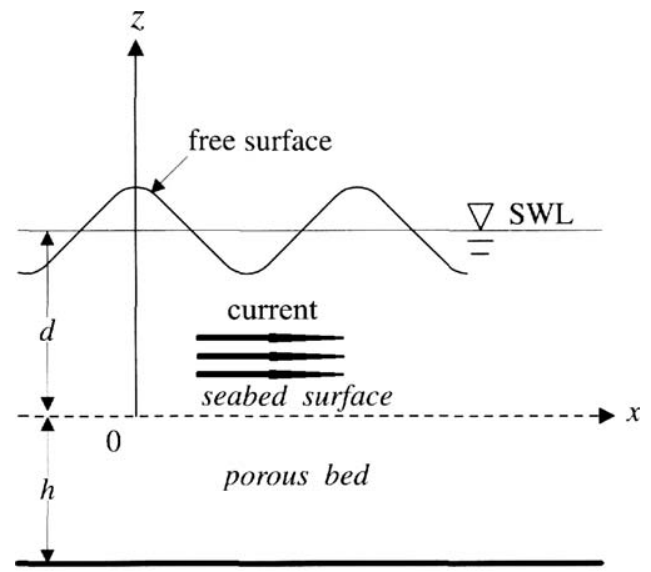

Rigid impermeable bottom

Figure 1. Definition of the whole problem.

$$
\begin{aligned}
& \sigma_{z}^{\prime}=2 G\left(\frac{\partial w}{\partial z}+\frac{\mu}{1-2 \mu} \varepsilon\right) \\
& \tau_{x z}=G\left(\frac{\partial u}{\partial x}+\frac{\partial w}{\partial z}\right)=\tau_{z x}
\end{aligned}
$$

where $\sigma_{x}^{\prime}$ and $\sigma_{z}^{\prime}$ are the effective stresses in $x$ and $z$ directions, respectively; $\tau_{x z}$ and $\tau_{z x}$ are shear stresses; $\mu$ is the Poisson's ratio; and $G$ is shear modulus of soil.

The force equilibrium in the absence of body force within the soil skeleton can be expressed in terms of soil displacements and pore pressure, as follows, according to the conception of effective stresses,

$$
\begin{gathered}
G\left(\frac{\partial^{2} u}{\partial x^{2}}+\frac{\partial^{2} u}{\partial z^{2}}\right)+\frac{G}{1-2 \mu} \frac{\partial \varepsilon}{\partial x}=\frac{\partial p}{\partial x}+\rho \frac{\partial^{2} u}{\partial t^{2}}, \\
G\left(\frac{\partial^{2} w}{\partial x^{2}}+\frac{\partial^{2} w}{\partial z^{2}}\right)+\frac{G}{1-2 \mu} \frac{\partial \varepsilon}{\partial z}=\frac{\partial p}{\partial z}+\rho \frac{\partial^{2} w}{\partial t^{2}},
\end{gathered}
$$

in which $\rho\left(=(1-n) \rho_{s}+n \rho_{f} ; \rho_{s}\right.$ is solid density $)$ is the density of soil. In Equations (7) and (8) the second terms on the right side are inertial terms, which have been ignored in most previous research (Jeng, 1997, 2003; Yamamoto et al., 1978).

\section{Boundary Conditions}

To determine the pore pressure $(p)$ and soil displacements $(u$, $w$ ) in governing Equations (1) and (7)-(8), appropriate boundary conditions are needed.

First, zero displacements and no vertical flow occur at the bottom of the seabed:

$$
u=w=0 \quad p=0 \quad \text { when } \quad z \rightarrow \infty \quad \text { for infinite thickness. }
$$

$u=w=0 \quad \frac{\partial p}{\partial z}=0 \quad$ when $\quad z=-h \quad$ for finite thickness.

Second, for the surface of the seabed, because the bottom frictional stress is assumed to be small and negligible in this study, vertical effective normal stress and shear stresses are zero, and pore pressure is equal to wave-associated bottom pressure:

$$
\sigma_{z}^{\prime}=\tau_{x z}=0 \quad p=p_{b}(x, t) \quad \text { when } \quad z=0,
$$

where $p_{b}(x, t)$ is produced by the third-order theory of wavecurrent interactions (Hsu et al., 2009),

$$
\begin{aligned}
p_{b}(x, t)= & \frac{\rho_{f} g H}{2 \cosh (k d)}\left[1-\frac{\omega_{2} k^{2} H^{2}}{2\left(U_{0} k-\omega_{0}\right)}\right] \cos (k x-\omega t) \\
& +\frac{3 \rho_{f} k H^{2}}{8}\left[\frac{\omega_{0}\left(\omega_{0}-U_{0} k\right)}{2 \sinh ^{4}(k d)} \frac{g k}{3 \sinh (2 k d)}\right] \cos 2(k x-\omega t) \\
& +\frac{3 \rho_{f} k H^{2} \omega_{0}\left(\omega_{0}-U_{0} k\right)}{512} \frac{\left[g-4 \sinh ^{2}(k d)\right]}{\sinh ^{7}(k d)} \cos 3(k x-\omega t) \\
& =\sum_{m=1}^{3} p_{m} \cos m(k x-\omega t),
\end{aligned}
$$


in which the intermediate frequency $\left(\omega_{0}, \omega_{2}\right)$ and wave frequency $(\omega)$ can be expressed as

$$
\begin{gathered}
\omega_{0}=U_{0} k+\sqrt{g k \tanh (k d)} \\
\omega_{2}=\frac{\left[9+8 \sinh ^{2}(k d)+8 \sinh ^{4}(k d)\right]}{64 \sinh ^{4}(k d)}\left(\omega_{0}-U_{0} k\right) \\
\omega=\omega_{0}+(k H)^{2} \omega_{2} .
\end{gathered}
$$

It is noted that Equation 13 will become the conventional wavedispersion relation without currents when $U_{0}=0 \mathrm{~m} / \mathrm{s}$.

\section{General Solutions}

Because the wave/current-induced seabed response basically fluctuates periodically, the wave/current-induced pore pressure $(p)$ and soil displacements $(u, w)$ can be assumed as the following forms (Madsen, 1978):

$$
\begin{aligned}
& u(x, z: t)=\sum_{m=1}^{3} p_{m} U_{m}(z) e^{i m(k x-\omega t)} \\
& w(x, z: t)=\sum_{m=1}^{3} p_{m} W_{m}(z) e^{i m(k x-\omega t)} \\
& p(x, z: t)=\sum_{m=1}^{3} p_{m} P_{m}(z) e^{i m(k x-\omega t)} .
\end{aligned}
$$

Substituting Equation (16) into Equations (1) and (7)-(8), the governing equations can be rewritten as

$$
\begin{gathered}
U_{m}^{\prime}-i m k W_{m}=a_{1 m} e^{\lambda_{1 m} z}+a_{2 m} e^{-\lambda_{1 m} z} \\
{\left[\left(\frac{\partial^{2}}{\partial z^{2}}-m^{2} k^{2}\right)\left(\frac{\partial^{2}}{\partial z^{2}}-m^{2} k^{2}+\alpha_{1 m}^{2}\right)+\alpha_{2 m}^{2}\right] U_{m}} \\
=\frac{G K \lambda_{1 m} \alpha_{3 m}}{2(1-\mu)}\left(a_{1 m} e^{\lambda_{1 m} z}-a_{2 m} e^{-\lambda_{1 m} z}\right) \\
i m k P_{m}=\frac{2 G(1-\mu)}{1-2 \mu}\left(U_{m}^{\prime \prime}-m^{2} k^{2} U_{m}\right) \\
+\rho m^{2} \omega^{2} U_{m}-\frac{G \lambda_{1 m}}{1-2 \mu}\left(a_{1 m} e^{\lambda_{1 m} z}-a_{2 m} e^{-\lambda_{1 m} z}\right)
\end{gathered}
$$

where the coefficients $\lambda_{1 m}$ and $\alpha_{i m}$ are given as

$$
\begin{gathered}
\lambda_{1 m}^{2}=m^{2}\left(k^{2}-\frac{\rho \omega^{2}}{G}\right) \\
\alpha_{1 m}^{2}=\frac{i m \omega \gamma_{\omega}}{K}\left[n \beta+\frac{1-2 \mu}{2 G(1-\mu)}\right]+\frac{\left(m^{2} k^{2}-\lambda_{1 m}^{2}\right)(1-2 \mu)}{2(1-\mu)} \\
\alpha_{2 m}^{2}=\frac{i m \omega \gamma_{\omega} n \beta(1-2 \mu)\left(m^{2} k^{2}-\lambda_{1 m}^{2}\right)}{2 K(1-\mu)}
\end{gathered}
$$

$\alpha_{3 m}=\left(\lambda_{1 m}^{2}-m^{2} k^{2}\right)+\frac{i m \omega \gamma_{\omega} n \beta}{K}-\frac{i m \omega(1-2 \mu)}{G K}\left(\gamma_{\omega}+i m \rho_{f} \omega K\right)$.

Then, the wave/current-induced effective normal stresses and shear stresses can be expressed as

$$
\begin{gathered}
\sigma_{x}^{\prime}=\sum_{m=1}^{3} \frac{2 G}{1-2 \mu}\left[i m k(1-\mu) U_{m}+\mu W_{m}^{\prime}\right] e^{i m(k x-\omega t)} \\
\sigma_{z}^{\prime}=\sum_{m=1}^{3} \frac{2 G}{1-2 \mu}\left[i m k \mu U_{m}+(1-\mu) W_{m}^{\prime}\right] e^{i m(k x-\omega t)} \\
\tau_{x z}=\sum_{m=1}^{3} G\left(2 i m k W_{m}+a_{1 m} e^{\lambda_{1 m} z}+a_{2 m} e^{-\lambda_{1 m} z}\right) e^{i m(k x-\omega t)}=\tau_{z x} .
\end{gathered}
$$

Through solving Equation 18, the general solution can be written as

$$
\begin{aligned}
U_{m}(z)= & \alpha_{4 m}\left(a_{1 m} e^{\lambda_{1 m} z}-a_{2 m} e^{-\lambda_{1 m} z}\right) \\
& +\left(b_{1 m} e^{\lambda_{2 m} z}+b_{2 m} e^{-\lambda_{2 m} z}\right)+\left(c_{1 m} e^{\lambda_{3 m} z}+c_{2 m} e^{-\lambda_{3 m} z}\right),
\end{aligned}
$$

where

$$
\begin{gathered}
\alpha_{4 m}=\frac{\lambda_{1 m} \alpha_{3 m}}{2(1-\mu)} \times \frac{1}{\left(\lambda_{1 m}^{2}-m^{2} k^{2}\right)\left(\lambda_{1 m}^{2}-m^{2} k^{2}+\alpha_{1 m}^{2}\right)+\alpha_{2 m}^{2}} \\
\lambda_{2 m}^{2}=\frac{1}{2}\left(-\alpha_{1 m}^{2}-\sqrt{\alpha_{1 m}^{4}-4 \alpha_{2 m}^{2}}+2 m^{2} k^{2}\right) \\
\lambda_{3 m}^{2}=\frac{1}{2}\left(-\alpha_{1 m}^{2}+\sqrt{\alpha_{1 m}^{4}-4 \alpha_{2 m}^{2}}+2 m^{2} k^{2}\right) .
\end{gathered}
$$

Substituting Equation (27) into Equation (17), the vertical soil displacement can be solved:

$$
\begin{aligned}
W_{m}(z)=-\frac{i}{m k}[ & \left(\lambda_{1 m} \alpha_{4 m}-1\right)\left(a_{1 m} e^{\lambda_{1 m} z}+a_{2 m} e^{-\lambda_{1 m} z}\right) \\
& +\lambda_{2 m}\left(b_{1 m} e^{\lambda_{2 m} z}-b_{2 m} e^{-\lambda_{2 m} z}\right) \\
& \left.+\lambda_{3 m}\left(c_{1 m} e^{\lambda_{3 m} z}-c_{2 m} e^{-\lambda_{3 m} z}\right)\right] .
\end{aligned}
$$

Finally, substituting Equation (27) into Equation (19), the pore pressure can be expressed as

$$
\begin{aligned}
P_{m}(z)=\frac{-2 i G(1-\mu)}{m k(1-2 \mu)}[ & \delta_{1 m}\left(a_{1 m} e^{\lambda_{1 m} z}-a_{2 m} e^{-\lambda_{1 m} z}\right) \\
& +\delta_{2 m}\left(b_{1 m} e^{\lambda_{2 m} z}+b_{2 m} e^{-\lambda_{2 m} z}\right) \\
& \left.+\delta_{3 m}\left(c_{1 m} e^{\lambda_{3 m} z}+c_{2 m} e^{-\lambda_{3 m} z}\right)\right],
\end{aligned}
$$

where

$$
\begin{gathered}
\delta_{1 m}=\frac{\alpha_{4 m}\left(\lambda_{1 m}^{2}-m^{2} k^{2}\right)-\lambda_{1 m}}{2(1-\mu)} \\
\delta_{2 m}=\lambda_{2 m}^{2}-m^{2} k^{2}+\frac{\left(m^{2} k^{2}-\lambda_{1 m}^{2}\right)(1-2 \mu)}{2(1-\mu)} \\
\delta_{3 m}=\lambda_{3 m}^{2}-m^{2} k^{2}+\frac{\left(m^{2} k^{2}-\lambda_{1 m}^{2}\right)(1-2 \mu)}{2(1-\mu)} .
\end{gathered}
$$

Equations (27) and (31)-(32) are the general solutions of the 
Table 1. Input data from the field observations.

\begin{tabular}{lccc}
\hline \hline & Case 1 & Case 2 & Case 3 \\
\hline Soil characteristics & & & \\
Soil permeability $K_{z}(\mathrm{~m} / \mathrm{s})$ & $2.8 \times 10^{-4}$ & $2.8 \times 10^{-4}$ & $2.8 \times 10^{-4}$ \\
Shear modulus $G\left(\mathrm{~N} / \mathrm{m}^{2}\right)$ & $1 \times 10^{8}$ & $1 \times 10^{8}$ & $1 \times 10^{8}$ \\
Saturation $S(-)$ & 0.992 & 0.992 & 0.992 \\
Poisson's ratio $\mu(-)$ & 0.33 & 0.33 & 0.33 \\
Soil porosity $n(-)$ & 0.33 & 0.33 & 0.33 \\
Soil depth $h(m)$ & 50 & 50 & 50 \\
Wave characteristics & & & \\
Wave period $T(\mathrm{~s})$ & 5.6 & 6.0 & 6.4 \\
Wave height $H(\mathrm{~m})$ & 0.9 & 0.84 & 0.79 \\
Water depth $d(\mathrm{~m})$ & 5.6 & 5.6 & 5.6 \\
\hline
\end{tabular}

wave/current-induced pore pressure and soil displacements. There are 18 unknown coefficients: $a_{i m}, b_{i m}$, and $c_{i m}(i=1-2$, $m=1-3)$. Through the new analytical solution proposed previously with boundary conditions in Equations (10) and (11), all the unknown coefficients can be solved. After the pore pressure and soil displacements are obtained, the effective normal stresses and shear stresses can be solved through Equations (24)-(26).

For the seabed of infinite thickness, with the boundary condition in Equation (9), the coefficients $a_{2 m}, b_{2 m}$, and $c_{2 m}$ are equal to zero. The rest of the coefficients, $a_{1 m}, b_{1 m}$, and $c_{1 m}$, can be solved analytically as

$$
\begin{gathered}
a_{1 m}=-2\left(\lambda_{2 m}-\lambda_{1 m}\right)\left[m^{2} k^{2} \mu+\lambda_{2 m} \lambda_{3 m}(1-\mu)\right] / M_{m} \delta_{0 m} \\
b_{1 m}=-\left\{2 \alpha_{4 m}\left(\lambda_{3 m}-\lambda_{1 m}\right)\left[m^{2} k^{2} \mu+\lambda_{3 m} \lambda_{1 m}(1-\mu)\right]\right. \\
\left.+\lambda_{3 m}(1-\mu)\left(2 \lambda_{1 m}-\lambda_{3 m}\right)+m^{2} k^{2} \mu\right\} / M_{m} \delta_{0 m} \\
c_{1 m}=-\left\{\begin{array}{c}
2 \alpha_{4 m}\left(\lambda_{1 m}-\lambda_{2 m}\right)\left[m^{2} k^{2} \mu+\lambda_{2 m} \lambda_{1 m}(1-\mu)\right] \\
\left.+\lambda_{2 m}(1-\mu)\left(\lambda_{2 m}-2 \lambda_{1 m}\right)-m^{2} k^{2} \mu\right\} / M_{m} \delta_{0 m},
\end{array}\right.
\end{gathered}
$$

where

$$
\begin{gathered}
\delta_{0 m}=-2 \delta_{1 m}\left(\lambda_{2 m}-\lambda_{1 m}\right)\left[m^{2} k^{2} \mu+\lambda_{2 m} \lambda_{3 m}(1-\mu)\right] \\
+\delta_{2 m}\left\{2 \alpha_{4 m}\left(\lambda_{1 m}-\lambda_{3 m}\right)\left[\lambda_{3 m} \lambda_{1 m}(1-\mu)+m^{2} k^{2} \mu\right]\right. \\
\left.+\lambda_{3 m}(1-\mu)\left(\lambda_{3 m}-2 \lambda_{1 m}\right)-m^{2} k^{2} \mu\right\} \\
+\delta_{3 m}\left\{2 \alpha_{4 m}\left(\lambda_{2 m}-\lambda_{1 m}\right)\left[\lambda_{2 m} \lambda_{1 m}(1-\mu)+m^{2} k^{2} \mu\right]\right. \\
\left.+\lambda_{2 m}(1-\mu)\left(\lambda_{2 m}-2 \lambda_{1 m}\right)+m^{2} k^{2} \mu\right\} \\
M_{m}=-\frac{2 i G(1-\mu)}{m k(1-2 \mu)} .
\end{gathered}
$$

\section{NUMERICAL RESULTS AND DISCUSSIONS}

The purpose of this study is to explore the influence of the combined wave and current loadings on soil response for a seabed of finite thickness. In this section the accuracy of the proposed model will be verified by first comparing it with the field observation and the previous numerical solution. Then, the effects of uniform currents and wave nonlinearity on the soil response will be discussed in detail. Finally, the effects of combined current and wave loadings on soil liquefaction will be discussed.

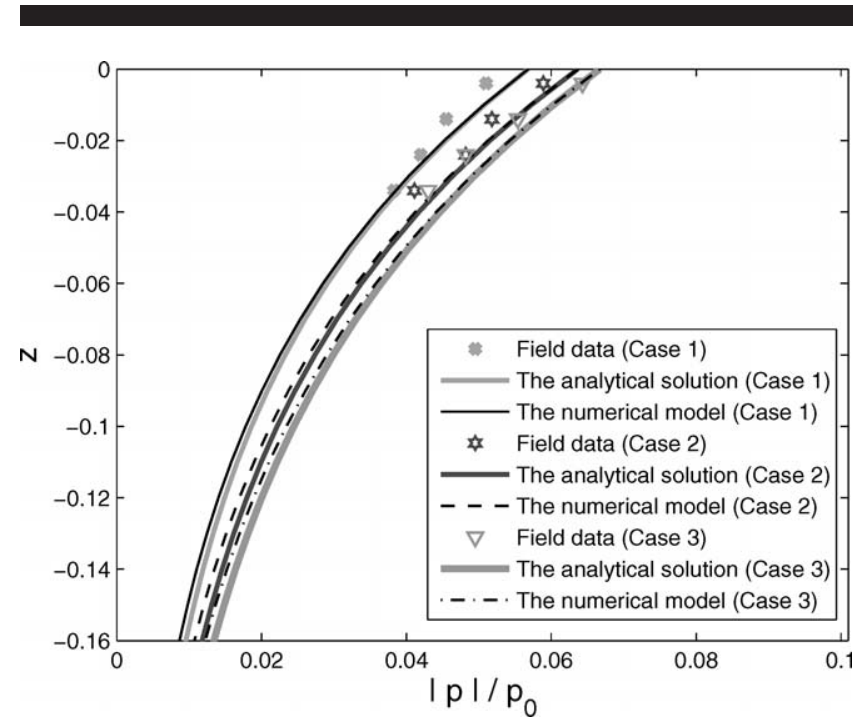

Figure 2. Vertical distributions of the maximum amplitude of the wave/ current-induced pore pressure $\left(|p| / P_{w s}\right) v s$. the soil relative depth $(z / h)$ for comparison with the field data and Jeng's numerical solution.

\section{Comparison with Field Observation and the Previous Numerical Solution}

A set of field observations for the wave-induced transient pore-water pressures near a seabed surface at a coast facing the Japan Sea was reported in Sakai et al. (1992). Herein, the pore pressures calculated from the present solution will be compared with the field data.

As mentioned in Sakai et al. (1992), there exist no currents in the field observations; the present solution will be reduced to only the wave loading. The input data from the field observations is listed in Table 1 . The seabed depth $(h)$ was not recorded in the field observations, but it is very deep, as the authors mentioned (Sakai et al., 1992). Therefore, this explains the value of the ones that use $50 \mathrm{~m}$ in this example. Because the wave height $(H)$ was not given in the paper, the wave height can be estimated according to the maximum amplitude of the bottom wave pressure. For example, the wave period $(T)$ is 5.6 $\mathrm{s}$, the $H$ is about $0.90 \mathrm{~m}$. Figure 2 presents a comparison of the pore pressures between the field data (Sakai et al., 1992) and the present model. Figure 2 also presents another comparison between the present model (with inertial forces) and the previous numerical solution (Jeng and Lin, 1996), which ignored the inertial terms.

As seen in this figure, the pore pressures in the present model are slightly higher than those from the field observations, although the trend of the present model agrees with the field observations. This may be because the pore-pressure gauges are covered with some small marine organics, as the author mentioned (Sakai et al., 1992). Another reason is that the wave height used in the present model is calculated by the linear wave theory because the waves during the observation were small, while the real wave may not be a linear wave. As shown in Figure 2, in the comparison of the wave-induced pore pressure between the present model and the previous numer- 


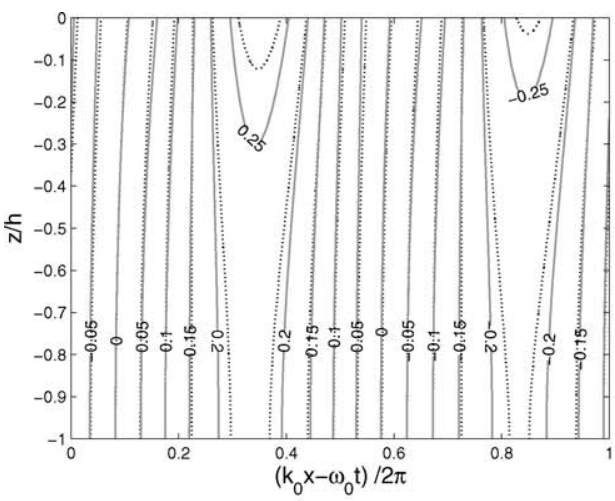

(a) $p / P_{w s}$

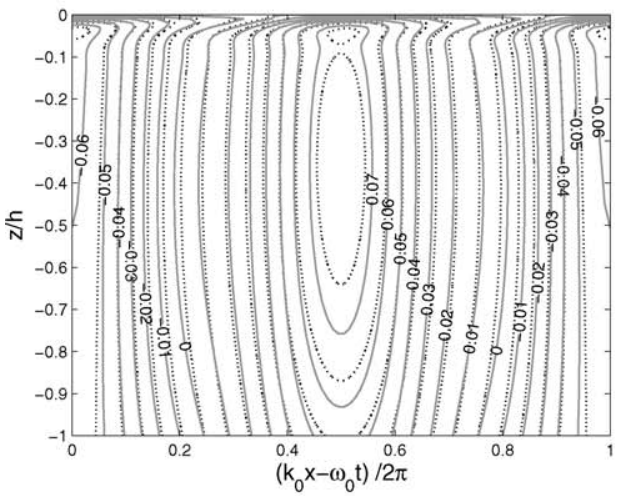

(c) $\sigma_{z}^{\prime} / P_{w s}$

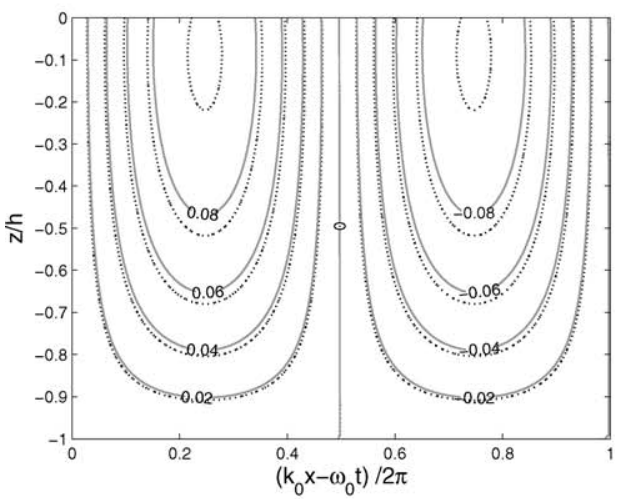

(e) $2 G k u / P_{w s}$

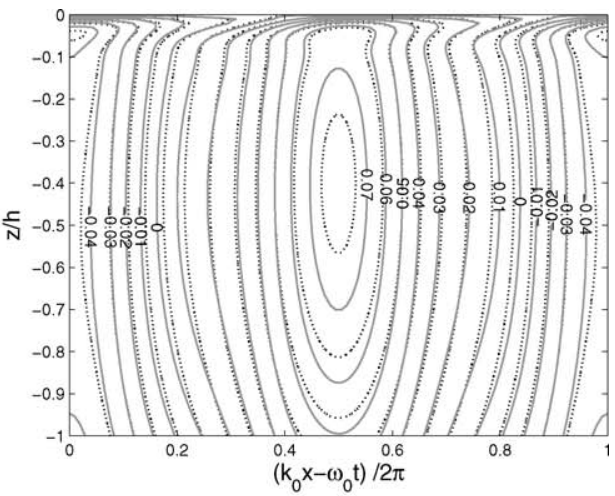

(b) $\sigma_{x}^{\prime} / P_{w s}$

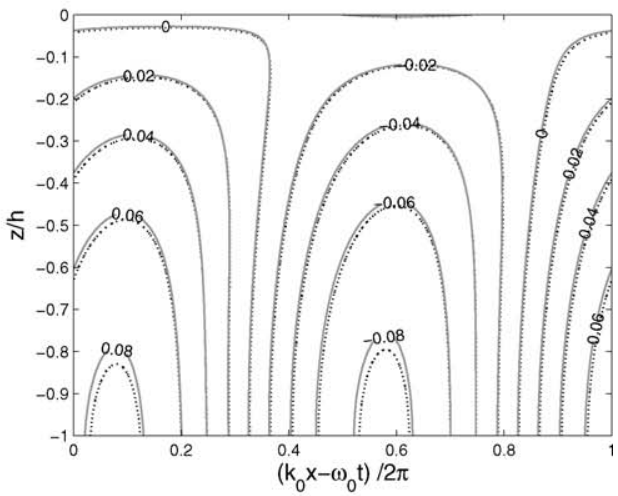

(d) $\tau_{x z} / P_{w s}$

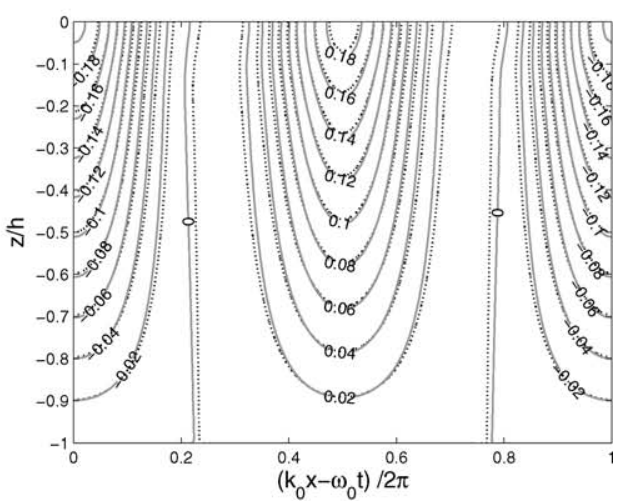

(f) $2 G k w / P_{w s}$

Figure 3. Contours of the wave/current-induced (a) $p / P_{w s}$, (b) $\sigma_{x}^{\prime} / P_{w s}$, (c) $\sigma_{z}^{\prime} / P_{w s}$, (d) $\tau_{x z} / P_{w s}$, (e) $2 G k u / P_{w s}$, and (f) $2 G k w / P_{w s}$ in coarse sand. '- ' is for the solution with currents $\left(U_{0}=1 \mathrm{~m} / \mathrm{s}\right)$, and '.. ' is for the solution without currents.

ical solution, a slight difference between the present analytical solution and the previous numerical model was observed, which can be considered as the verification of the present model from another perspective.

\section{Effects of Currents}

One of the objectives of this paper is to examine the effects of currents on the seabed response in a porous seabed. Figures 3 and 4 illustrate the contours of wave/current-induced seabed 


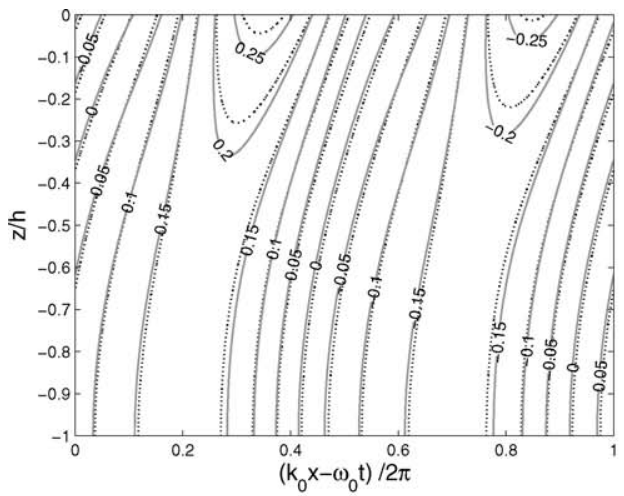

(a) $p / P_{w s}$

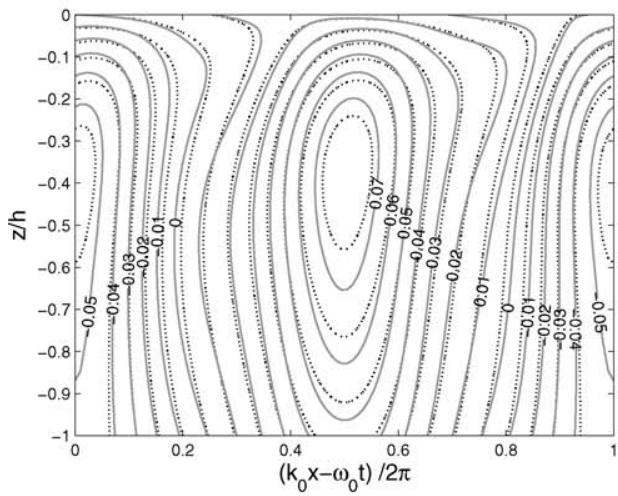

(c) $\sigma_{z}^{\prime} / P_{w s}$

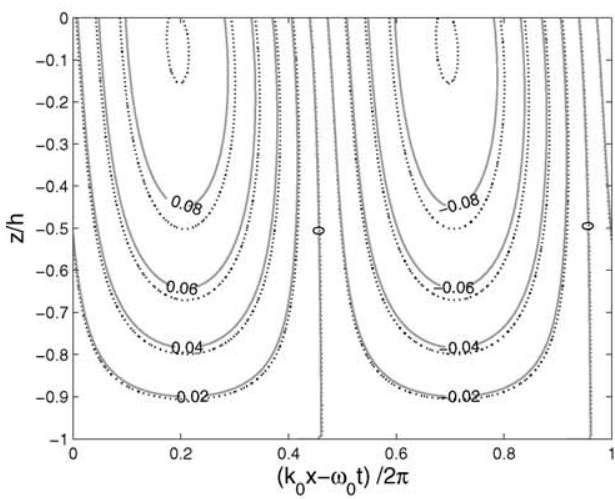

(e) $2 G k u / P_{w s}$

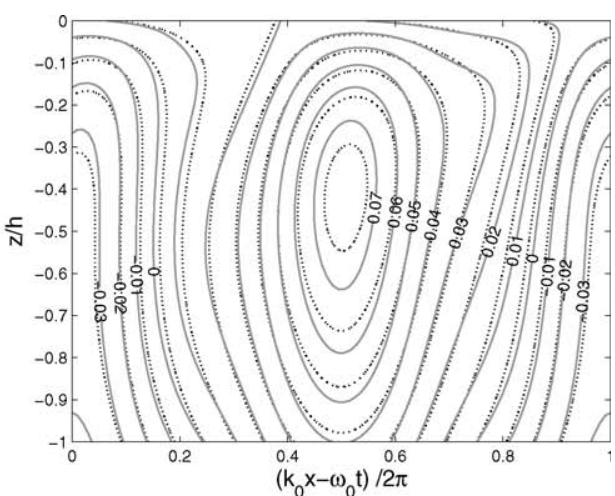

(b) $\sigma_{x}^{\prime} / P_{w s}$

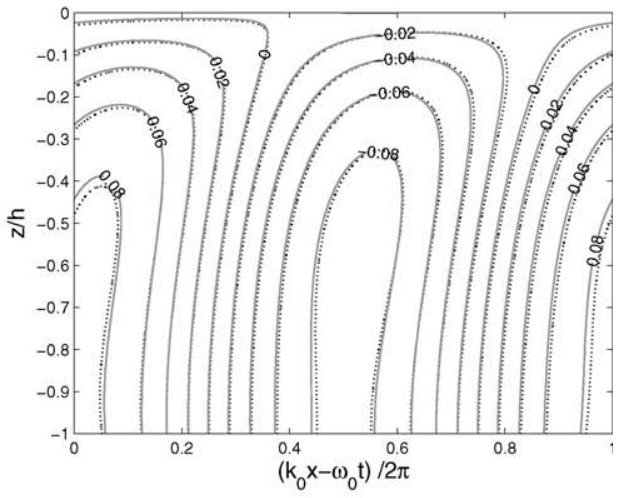

(d) $\tau_{x z} / P_{w s}$

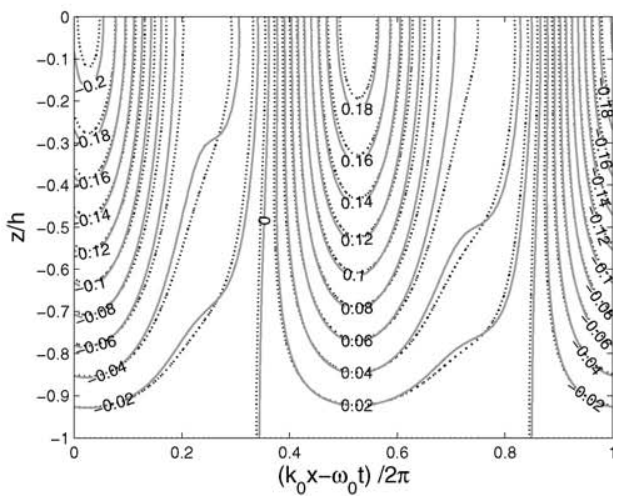

(f) $2 G k w / P_{w s}$

Figure 4. Contours of the wave/current-induced (a) $p / P_{w s}$, (b) $\sigma_{x}^{\prime} / P_{w s}$, (c) $\sigma_{z}^{\prime} / P_{w s}$, (d) $\tau_{x z} / P_{w s}$, (e) $2 G k u / P_{w s}$, and (f) $2 G k w / P_{w s}$ in fine sand. '- is for the solution with currents $\left(U_{0}=1 \mathrm{~m} / \mathrm{s}\right)$, and '.. ' is for the solution without currents.

response (including pore pressure, effective normal stresses, shear stresses, and soil displacements) with and without currents in coarse and fine sand, respectively. In Figures 3 and $4, k_{0}$ and $\omega_{0}$ are the wave number and wave frequency calculated by the linear wave theory without a current. The major parameters of the wave conditions used in these two figures (Figures 3 and 4) are as follows: $d=10 \mathrm{~m}, H=5 \mathrm{~m}, T=10$ s. The major parameters of the soil conditions are $h=10 \mathrm{~m}, \mu=$ $0.4, n=0.333$, and $S=0.975$. The soil permeability $(K)$ of coarse and fine sand is $10^{-2} \mathrm{~m} / \mathrm{s}$ and $10^{-4} \mathrm{~m} / \mathrm{s}$, while the shear modulus 


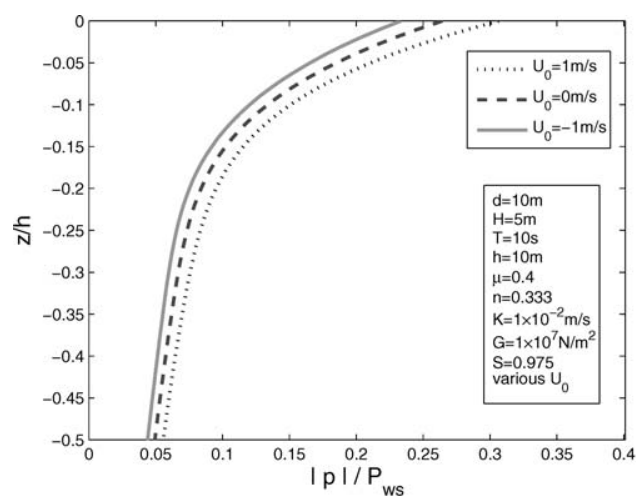

(a) $|p| / P_{w s}$

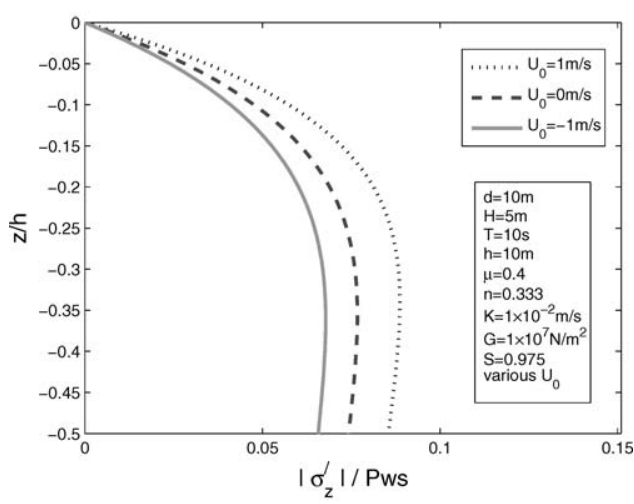

(b) $\left|\sigma_{z}^{\prime}\right| / P_{w s}$

Figure 5. Vertical distributions of the maximum amplitude of the wave/ current-induced (a) $|p| / P_{w s}$ and (b) $\left|\sigma_{z}^{\prime}\right| / P_{w s} v s$. the soil relative depth $(z / h)$ for direction of current $\left(U_{0}\right)$ in coarse sand.

(G) of coarse and fine sand is $10^{7} \mathrm{~N} / \mathrm{m}^{2}$ and $5 \times 10^{6} \mathrm{~N} / \mathrm{m}^{2}$, respectively. In Figures 3 and 4, pore pressure, effective normal stresses, shear stresses, and soil displacements are all nondimensional by the static water pressure $\left(P_{w s}=\gamma_{\omega} d\right)$.

As seen in Figures 3 and 4, it is clear that the influence of the currents on all the wave/current-induced seabed response (including pore pressure, effective normal stresses, shear stresses, and soil displacements) is significant both in coarse and fine sand under a specific wave and soil condition. With the existence of currents, the effects of phase lags will be enhanced, and most contour lines will expand their contour values, which is not limited to the peak value. This phenomenon becomes more significant in the vertical soil displacement (e.g., Figure 4f). That is, the influence of currents not only affects the amplitude of the wave/current-induced seabed response but also the distribution of the space region. The reason lies in that the existence of currents will change the distribution of flow in the designated areas. According to the potential flow theory, the wave pressure acting on the seabed will change significantly when currents exist. As a result, the pore pressure and effective stresses in the seabed will be changed. Furthermore, the effect of phase lags in fine sand is more obvious than that in coarse

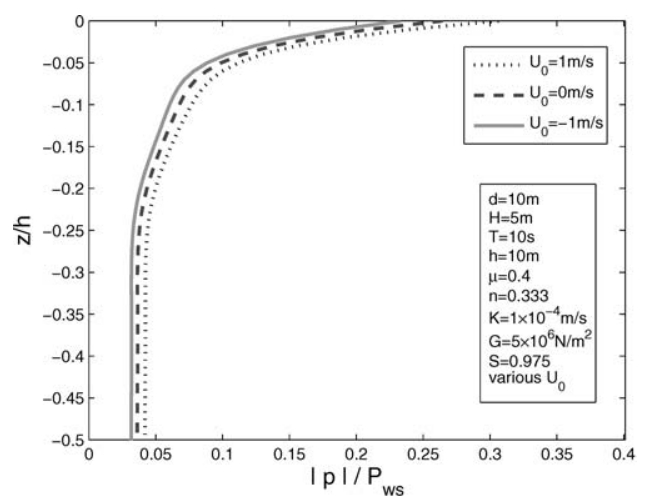

(a) $|p| / P_{w s}$

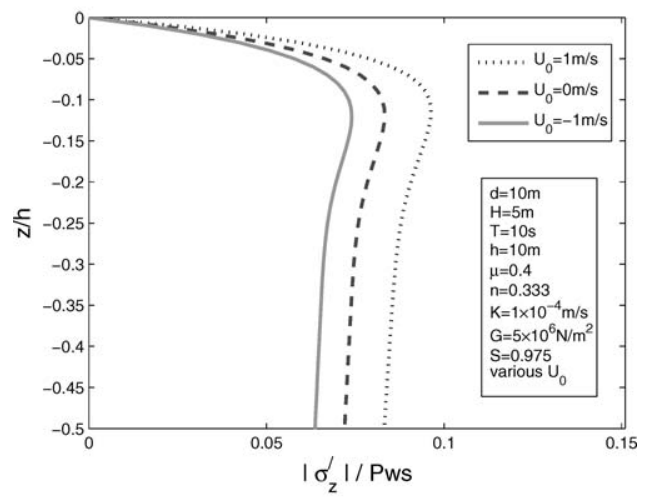

(b) $\left|\sigma_{z}^{\prime}\right| / P_{w s}$

Figure 6. Vertical distributions of the maximum amplitude of the wave/ current-induced (a) $|p| / P_{w s}$ and (b) $\left|\sigma_{z}^{\prime}\right| / P_{w s} v s$. the soil relative depth $(z / h)$ for direction of current $\left(U_{0}\right)$ in fine sand.

sand, which is caused by the lower soil permeability in fine sand.

As to the effect of the direction of currents, the direction significantly affects the wave/current-induced pore pressure and vertical effective normal stress both in coarse and fine sand, as shown in Figures 5 and 6 . The relative difference of the maximum pore pressure between different direction currents reaches $8 \%$ of the static wave pressure at the seabed surface. Furthermore, the maximum relative difference of vertical effective normal stress may reach $3 \%$ of the static wave pressure, as shown in Figures 5 and 6.

\section{Effects of Wave Nonlinearity}

Another object of this study is to investigate the effects of wave nonlinearity. Here, the third-order wave theory is used in the numerical examples. Figures 7 and 8 show the contours of wave-induced seabed response (including pore pressure, effective normal stresses, shear stresses, and soil displacements) in coarse and fine sand without currents, respectively. In the figures the input data is the same as that in Figures 3 and 4 . 


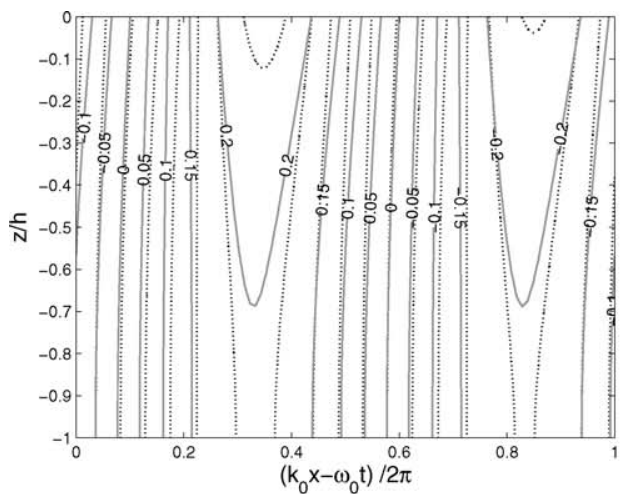

(a) $p / P_{w s}$

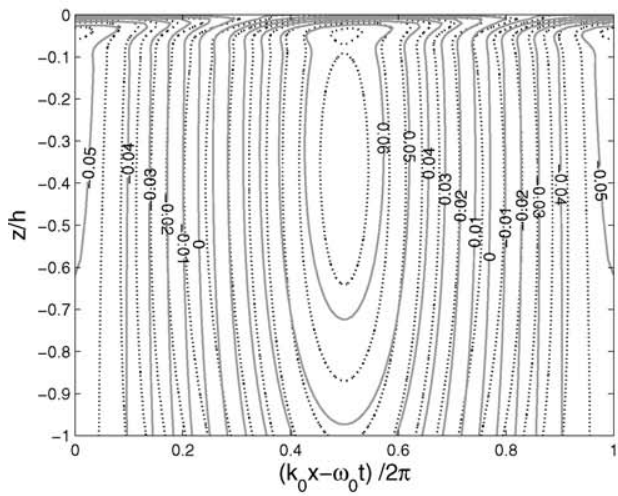

(c) $\mid \sigma_{z}^{\prime} / P_{w s}$

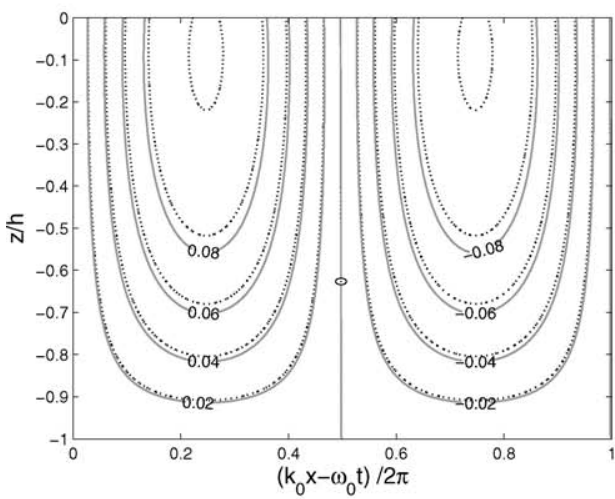

(e) $2 G k u / P_{w s}$

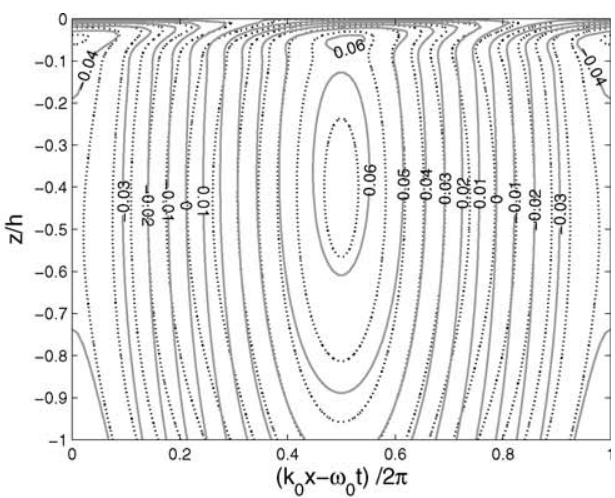

(b) $\sigma_{x}^{\prime} / P_{w s}$

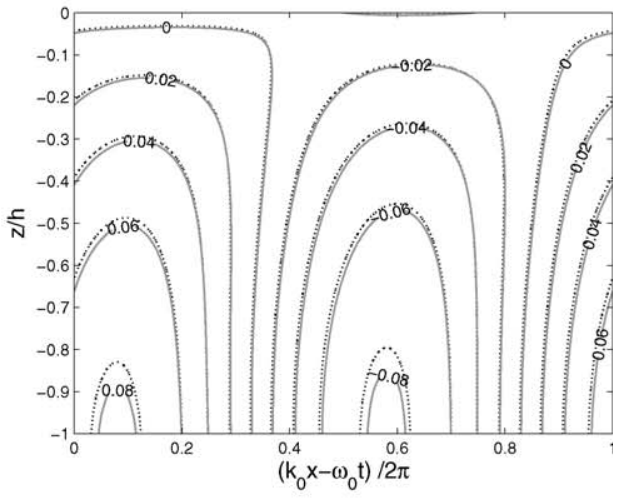

(d) $\tau_{x z} / P_{w s}$

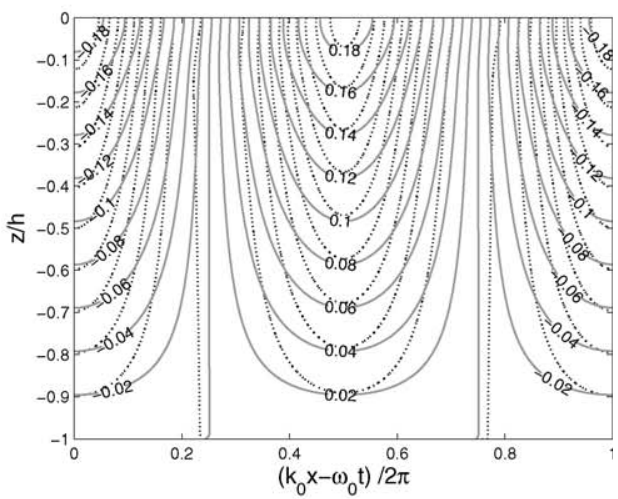

(f) $2 G k w / P_{w s}$

Figure 7. Contours of the wave-induced (a) $p / P_{w s}$, (b) $\sigma_{x}^{\prime} / P_{w s}$, (c) $\sigma_{z}^{\prime} / P_{w s}$, (d) $\tau_{x z} / P_{w s}$, (e) $2 G k u / P_{w s}$, and (f) $2 G k w / P_{w s}$ in coarse sand without currents. '- ' is for the solution with linear waves, and '...' is for the solution with third-order waves.

These two figures also clearly indicate that the effects of third-order wave components are significant, especially on effective normal stresses and vertical soil displacement (e.g., Figures 7b, 7c, and 7f). The values of wave-induced seabed response under third-order wave loading are greater than those under linear wave loading. This is because the thirdorder wave loading considers the high-order terms. Similarly, the third-order wave components also affect the distribution of 


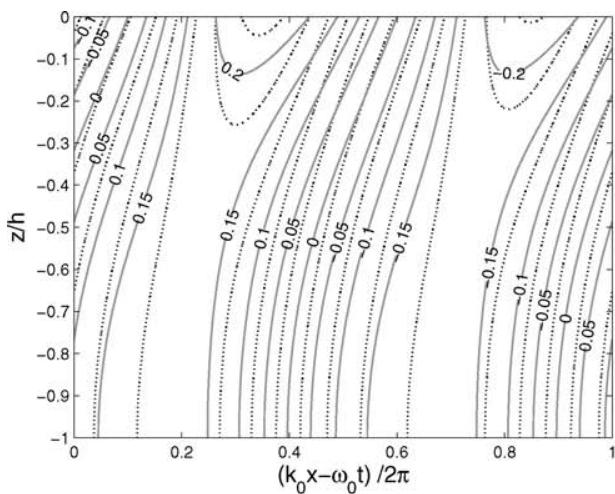

(a) $p / P_{w s}$

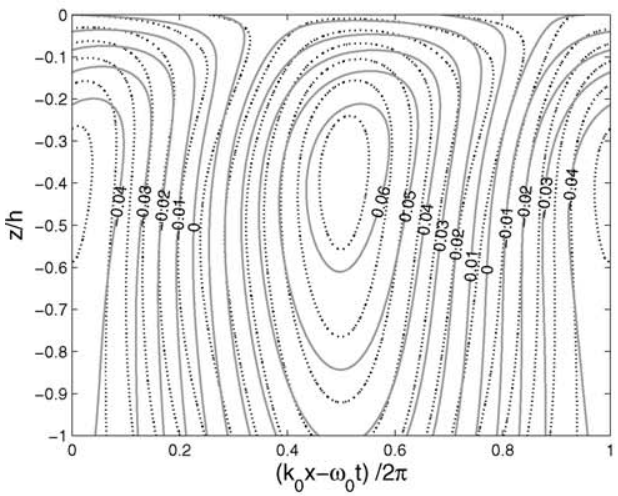

(c) $\sigma_{z}^{\prime} / P_{w s}$

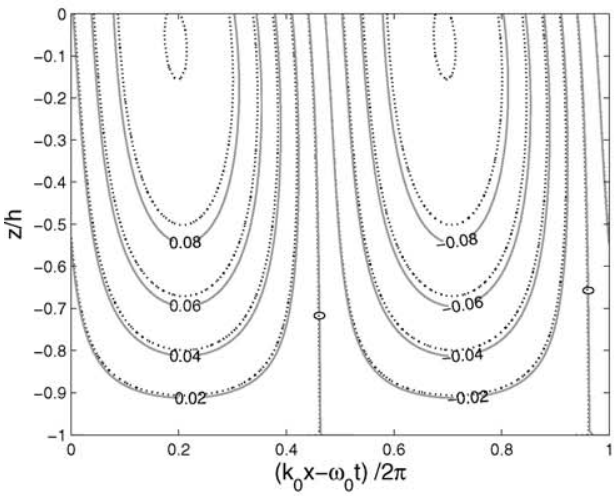

(e) $2 G k u / P_{w s}$

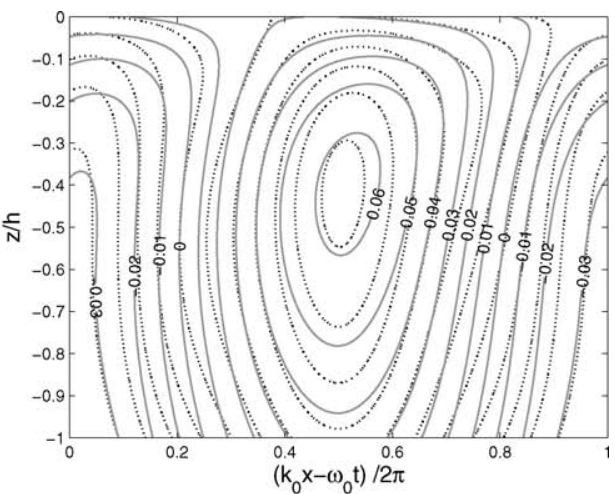

(b) $\sigma_{x}^{\prime} / P_{w s}$

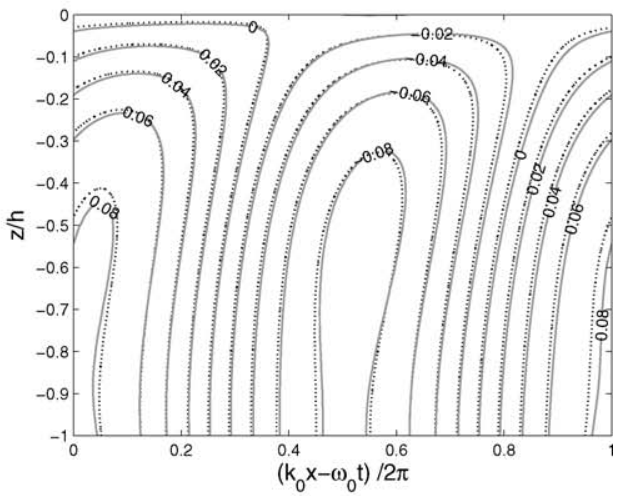

(d) $\tau_{x z} / P_{w s}$

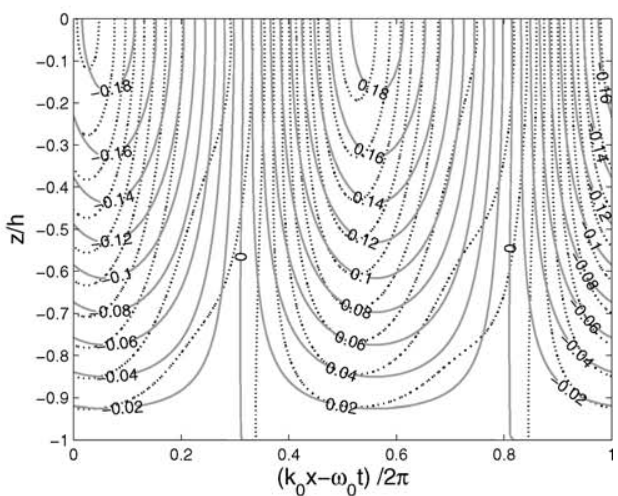

(f) $2 G k w / P_{w s}$

Figure 8. Contours of the wave-induced (a) $p / P_{w s}$, (b) $\sigma_{x}^{\prime} / P_{w s}$, (c) $\sigma_{z}^{\prime} / P_{w s}$, (d) $\tau_{x z} / P_{w s}$, (e) $2 G k u / P_{w s}$, and (f) $2 G k w / P_{w s}$ in fine sand without currents. '- ' is for the solution with linear waves, and '...' is for the solution with third-order waves.

the space region. The effect of phase lags in fine sand is more obvious than that in coarse sand.

The relative difference concerning wave(current)-induced pore pressures between third-order waves and linear waves theory for different wave height $(H)$ both in coarse sand and fine sand will also be discussed in this section, and Figures 9 and 10 show the results. In the figures (Figures 9 and 10), $\Delta p\left(=p_{3 \mathrm{rd}}-p_{1 \mathrm{st}}\right)$ is the relative difference of pore pressures between the third-order wave and linear wave, which is nondimensional by the value of linear wave(current)-induced 


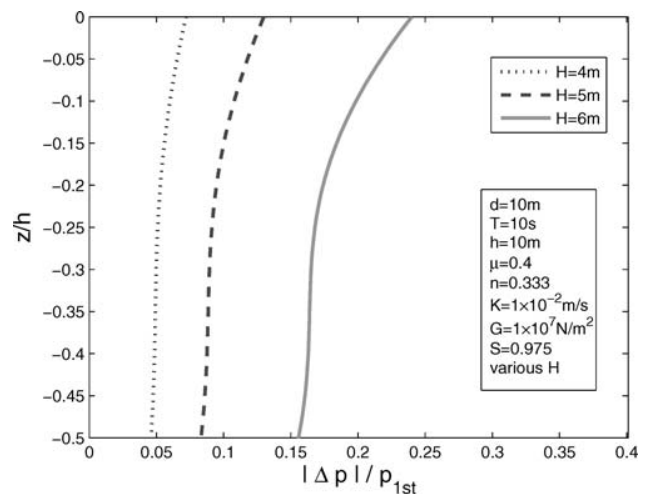

(a) $U_{0}=0 \mathrm{~m} / \mathrm{s}$

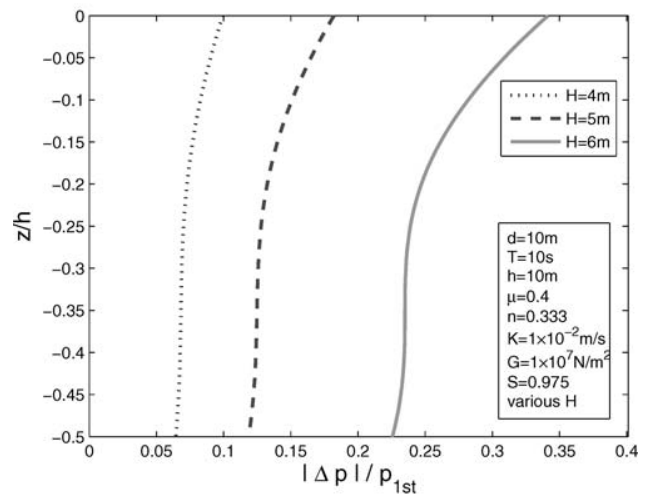

(b) $U_{0}=1 \mathrm{~m} / \mathrm{s}$

Figure 9. Relative difference concerning wave(current)-induced pore pressures $\left(\Delta p / p_{1 \mathrm{st}}\right)$ between third-order waves and linear waves theory $v s$ the soil relative depth $(z / h)$ for different wave height $(H)$ in coarse sand.

pore pressure $\left(p_{1 \text { st }}\right)$. As shown in these figures, the wave height has a significant influence on the pore pressure in both soil types. With the increase of the wave height, the relative difference concerning pore pressures between third-order waves and linear waves will increase. Furthermore, currents will expand this influence significantly.

\section{Soil Liquefaction}

Soil liquefaction is particularly important to practical engineers involved in the design of the foundation of marine infrastructures because the maximum liquefaction depth reflects many questions. Therefore, it is necessary to explore the influence of currents and third-order waves on soil liquefaction.

The excess pore pressure $\left(u_{e}\right)$ has been recognized as the main factor causing the instability of the seabed (Rahman, 1997), which can be calculated by taking into account the variation of the wave pressure at the seabed surface as follows:

$$
u_{e}=-\left(P_{b}-p\right) \text {. }
$$

As to the liquefaction criterion, this study uses the criterion proposed by Zen and Yamazaki (1990),

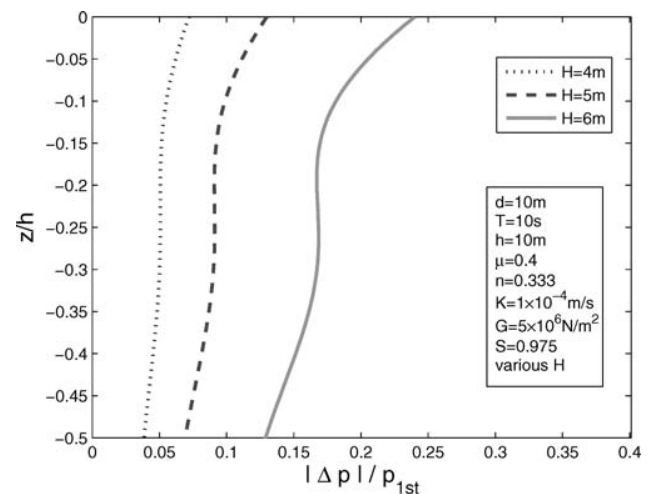

(a) $U_{0}=0 \mathrm{~m} / \mathrm{s}$

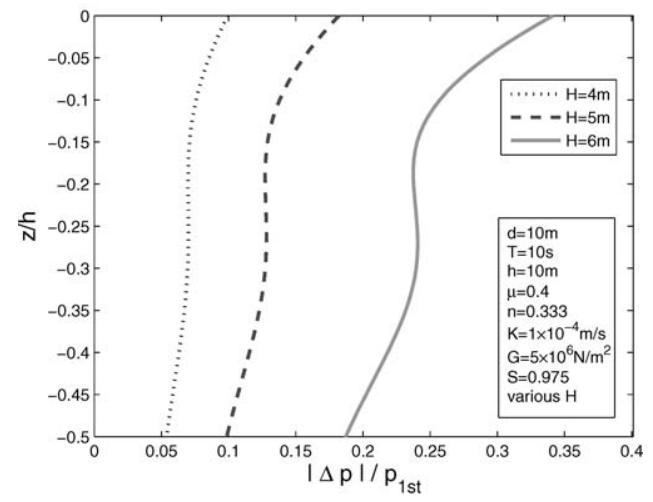

(b) $U_{0}=1 \mathrm{~m} / \mathrm{s}$

Figure 10. Relative difference concerning wave(current)-induced pore pressures $\left(\Delta p / p_{1 \mathrm{st}}\right)$ between third-order waves and linear waves theory $v s$. the soil relative depth $(z / h)$ for different wave height $(H)$ in fine sand.

$$
-\frac{1}{3}\left(\gamma_{s}-\gamma_{w}\right)\left(1+2 K_{0}\right) z \leq u_{e}
$$

where $\gamma_{\mathrm{s}}$ and $\gamma_{\omega}$ are the unit weights of the soil and water, respectively. $K_{0}$ is the coefficient of lateral earth pressure at rest, the value of which is 0.5 in this study.

Figure 11 illustrates the influence of currents and third-order waves on soil liquefaction. In the figure, $L_{0}$ is the wavelength calculated by the linear wave theory without a current, and the influence of currents on soil liquefaction is significant. The relative difference of maximum liquefaction depth between the situation with and without currents can reach $19 \%$ of the maximum liquefaction depth without currents. Figure $11 \mathrm{~b}$ illustrates the influence of third-order waves. Similarly, the influence of third-order waves is also significant on soil liquefaction. The relative difference of maximum liquefaction depth between the situation under third-order wave loading and linear wave loading may reach $7.7 \%$ of the maximum liquefaction depth under linear wave loading.

\section{CONGLUSIONS}

In this paper inertial terms are included in poro-elastic model, while the combined wave and current loadings are 


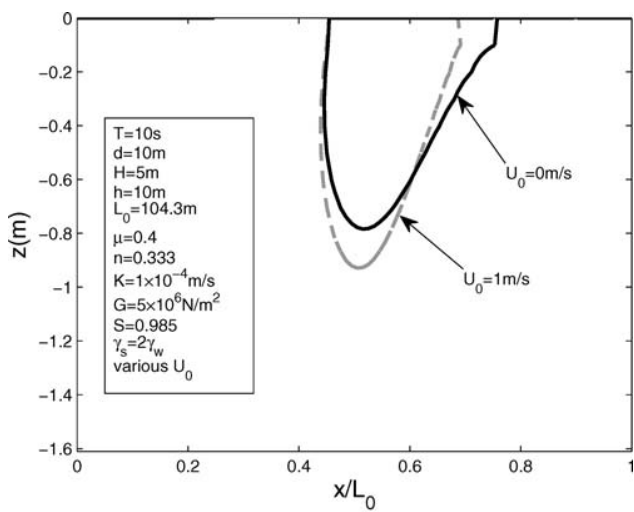

(a)

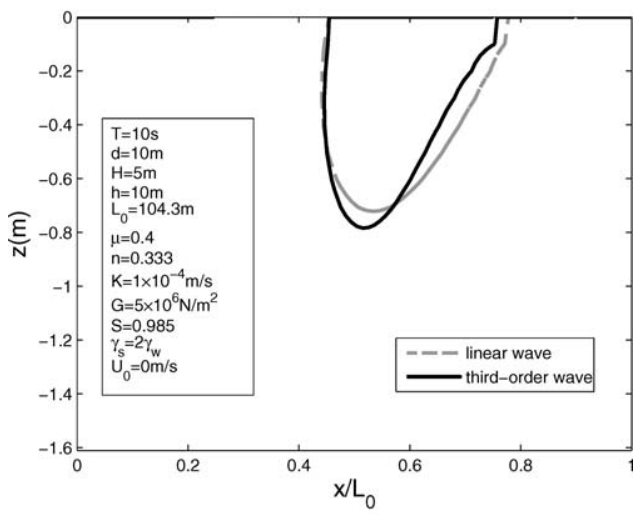

(b)

Figure 11. Influence of currents and third-order waves on soil liquefaction.

considered in the boundary conditions. A new analytical solution of the whole problem with finite thickness can be gained. Based on the proposed new analytical solution and the numerical results, the following conclusions can be drawn.

(1) The new analytical solution for the $u-p$ problem under third-order wave and current loadings with finite depth is proposed. The new solution is verified with the field data (Sakai et al., 1992) and the numerical solution (Jeng and Lin, 1996) without currents.

(2) The influence of currents is significant on all the wave/ current-induced seabed responses in both coarse and fine sand, as shown in Figures 3 and 4. This influence affects both the magnitude and spatial distributions of the waveinduced seabed response.

(3) The direction of currents significantly affects the wave/ current-induced pore pressure and vertical effective stress (Figures 5 and 6). The relative difference of the maximum pore pressure between different direction currents reaches $8 \%$ of the static wave pressure at the seabed surface.

(4) The influence of wave nonlinearity is significant on all the wave-induced seabed responses both in coarse and fine sand (Figures 7 and 8). With the increase of the wave height, the relative difference concerning wave(current)-induced pore pressures between third-order waves and linear waves theory will increase (Figures 9 and 10). Furthermore, currents will expand this influence significantly.

(5) Comparing Figures 3 and 4, the effect of phase lags in fine sand is more obvious than that in coarse sand, which is caused by the lower soil permeability in fine sand.

(6) Both currents and third-order waves have a huge influence on soil liquefaction (Figure 11). The relative difference of maximum liquefaction depth between the situation with and without currents can reach $19 \%$ of the maximum liquefaction depth without currents. Therefore, currents and high-order wave components cannot always be ignored, especially in shallow water.

\section{ACKNOWLEDGMENTS}

We are grateful for the support from the State Key Laboratory of Ocean Engineering Self-Development Grant \#GKZD010053 (2011), Scotland-China Exchange Program (2010-2011), Sichuan University State Key Laboratory of Hydraulics and Mountain River Engineering Open Fund Scheme \#SKLH-OF-1005 (China), and National Natural Science Foundation of China (NSFC) Grant \#41176073 (China).

\section{LITERATURE CITED}

Biot, M.A., 1941. General theory of three-dimensional consolidation. Journal of Applied Physics, 26(2), 155-164.

Biot, M.A., 1956. Theory of propagation of elastic waves in a fluidsaturated porous solid, part 1: low frequency range. Journal of Acoustic Society, American, 28, 168-177.

Cuomo, G.; Allosp, W., and Takahashi, S., 2010. Scaling wave import pressures on vertical walls. Coastal Engineering, 57, 604-609.

Hsu, H.C.; Chen, Y.Y.; Hsu, J.R.C., and Tseng, W.J., 2009. Non-linear water waves on uniform current in Lagrangian coordinates. Journal of Nonlinear Mathematical Physics, 16, 47-61.

Jeng, D.S., 1997. Soil response in cross-anisotropic seabed due to standing waves. Journal of Geotechnical and Geoenvironmental Engineering, ASCE, 123(1), 9-19.

Jeng, D.-S., 2003. Wave-induced seafloor dynamics. Applied Mechanics Review, 56(4), 407-429.

Jeng, D.S. and Cha, D.H., 2003. Effects of dynamic soil behavior and wave non-linearity on the wave-induced pore pressure and effective stresses in porous seabed. Ocean Engineering, 30(16), 2065-2089.

Jeng, D.S. and Lin, Y.S., 1996. Finite element modelling for water waves-soil interaction. Soil Dynamics and Earthquake Engineering, 15(5), 283-300.

Jeng, D.S. and Rahman, M.S., 2000. Effective stresses in a porous of finite thickness: inertia forces. Canadian Geotechnical Journal, 37(6), 1383-1392.

Jeng, D.S. and Seymour, B.R., 1997. Response in seabed of finite depth with variable permeability. Journal of Geotechnical and Geoenvironmental Engineering, ASCE, 123(10), 427-440.

Jeng, D.S.; Rahman, M.S., and Lee, T.L., 1999. Effects of inertia forces on wave-induced seabed response. International Journal of Offshore and Polar Engineering, 9(4), 307-313.

Kitano, T. and Mase, H., 1999. Boundary layer theory for anisotropic seabed response to sea waves. Journal of Waterway, Port, Ocean and Coastal Engineering, ASCE, 125(4), 187-194.

Kudella, M.; Onmeraci, H.; de Groot, M.B., and Meijers, P., 2006. Large-scale experiments on pore pressure generation underneath a Caisson breakwater. Journal of Waterway, Port, Ocean and Coastal Engineering, ASCE, 132(4), 310-324.

Lundgren, H.; Lindhardt, J.H.C., and Romold, C.J., 1989. Stability of breakwaters on porous foundation. In: Proceedings of 12th 
International Conference on Soil Mechanics and Foundation (Rio De Janeiro), pp. 451-454.

Madsen, O.S., 1978. Wave-induced pore pressure and effective stresses in a porous bed. Geotechnique, 28(4), 377-393.

Rahman, M.S., 1997. Instability and movement of oceanfloor sediments: a review. International Journal for Offshore and Polar Engineering, 7(3), 220-225.

Sakai, T.; Mase, H.; Cox, H.D.T., and Ueda, Y., 1992. Field observation of wave-induced porewater pressures. In: Proceedings of 23th International Conference on Coastal Engineering (Venice), pp. $220-225$.

Sassa, S.; Takayama, T.; Mizutani, M., and Tshjio, D., 2006. Field observation of the build-up and dissipation of residual pore water pressures in seabed sands under the passage of storm waves. Journal of Coastal Research, 39, 410-414.

Silvester, R. and Hsu, J.R.C., 1989. Sines revisited. Journal of Waterways, Port, Coastal and Ocean Engineering, ASCE, 115(3), 327-344.

Sumer, B.M. and Fredsoe, J., 2002. The Mechanics of Scour in Marine Environment. New Jersey: World Scientific, 536p.
Ulker, M.B.C.; Rahman, M.S., and Jeng, D.S., 2009. Wave-induced response of seabed: various formulations and their applicability. Applied Ocean Research, 31(1), 12-24.

Wen, F.; Jeng, D.-S., and Wang, J.H., 2012. Response of a saturated seabed around offshore pipeline under combined wave and current loading. Applied Ocean Research, 35, 25-37.

Yamamoto, T.; Koning, H.L.; Sellmeiher, H., and van Hijum, E.V., 1978. On the response of a poro-elastic bed to water waves. Journal of Fluid Mechanism, 87, 193-206.

Zen, K. and Yamazaki, H., 1990. Mechanism of wave-induced liquefaction and densification in seabed. Soils and Foundations, 30(4), 90-104.

Zhang, J.M.; Zhang, J.H.; Wang, G., and Chen, Y., 2009. Safety evaluation of breakwaters based on physical and numerical modelling. Ocean Engineering, 36, 852-862.

Zienkiewicz, O.C.; Chang, C.T., and Bettess, P., 1980. Drained, undrained, consolidating and dynamic behavior assumptions in soils. Geotechnique, 30(4), 385-395. 